\title{
FINESTRA ENDINS I ENFORA: SOBRE ALGUNES PROTAGONISTES DE MONTSERRAT ROIG
}

\author{
MARIA ÀNGELS FRANCÉS DÍEZ \\ Universitat d'Alacant
}

\section{DESPRÉS DEL SILENCI}

De l'escriptora i periodista Montserrat Roig s'ha dit que dedica l'obra literària a una delicada tasca d'excavació a través de capes de silenci que, com un palimpsest, amaguen històries mai no escrites. Profundament arrelada a la ciutat de Barcelona, dibuixa personatges femenins que també senten per la ciutat una atracció intensa, que hi estableixen una relació conflictiva -pel que té de vedada. El que ella denomina el perfum d'una història oblidada, marginada de la crònica oficial -la percepció de personatges femenins enclaustrats en l'interior dels sumptuosos pisos burgesos del l'Eixample barceloní- passen d'objecte a subjecte en les pàgines de les seues novel-les, subverteixen l'ordre establert per segles de bons costums en un intent de testimoniar una altra memòria, d'arrelar en una genealogia femenina confinada en l'àmbit privat la posterior invasió de l'espai públic de la qual Roig, com a intel-lectual, periodista, feminista, conferenciant, escriptora... és pionera.

\section{ESPAIS I GĖNERE: EN ELS PATIS INTERIORS DE L'EIXAMPLE}

La crònica oficial margina a consciència una part de la història de les ciutats que mai no ha ocupat les pàgines de cap diari, de cap prestigiosa enciclopèdia. Com assenyala Janet Wolff, ${ }^{1}$ la literatura de la modernitat descriu la consciència masculina de les transformacions del món públic i el privat, la separació de les esferes amb l'aparició de les institucions dirigides per i per als homes. Wolff es lamenta de la pobresa d'una crònica que ignora la diferent experiència de l'altra meitat de la població de les ciutats. Roig percep aquesta mateixa absència:

1. WolfF, Janet: "The Invisible Flâneuse. Women and the Literature of Modernity», en Feminine Sentences. Essays on Women and Culture, Los Angeles, University of California Press, 1990, p. 34. 
"Quan va obrir-se el camp de visió de la meva infantesa, que fins aleshores havia estat, en gran mesura, limitat pels patis interiors de l'Eixample, vaig començar a imaginar-me totes aquelles mirades de dones, la percepció visual de les quals a penes si ens ha deixat algun rastre. D'aquesta manera, les ciutats perden part de la seva història, de la seva memòria». ${ }^{2}$

Des del seu emplaçament públic com a flanêuse impenitent de la ciutat de Barcelona, Roig s'imagina en el marc d'una petita finestra gòtica el rostre d'una dona del segle XIV, observant l'espectacle del carrer o la plaça, badallant potser a l'espera del marit que torna de la mar o inquieta davant la possibilitat d'albirar un amant que no pot atrapar. "Dona finestrera, es cansa de ser soltera", diu el refrany popular que cita. Era perillós, aquest espai llindar, frontera, que és la finestra, l'obertura al món de les dones confinades a l'interior de les seues cases. Quasi tan perillós com el balcó, autèntic espai de transició suspés entre el mur de la casa i l'aire del carrer. El món exterior sempre és font de temptacions gens profitoses per a la naturalesa dèbil i pecaminosa de la dona, una de les propietats més importants de l'home i la que més convenia vigilar si volia conservar el seu honor (el de l'home) intacte. En arquitectura, açò es tradueix en directrius com les del tractat d'Alberti, del segle XV. Sobre la dona, Alberti escrivia que calia tancar-la en les profunditats d'una seqüència d'espais, a la distància més gran possible del món exterior, mentre que aquest espai havia de ser el regne de l'home, més preparat per als afers públics. La casa, en el seu tractat, s'entén com un mecanisme de domesticació. ${ }^{3}$

Roig és conscient d'aquest procés:

«La dona que baixava a la plaça a l'Edat Mitjana, filava al carrer i xafardejava amb les veïnes, l'han tancada lentament dins la llar: si no vol que l'acusin de bruixa, haurà de ser discreta, assenyada, estalviadora i respectuosa amb la nova moral ciutadana. El carrer, clamen els moralistes, és ple de perills, i ella hi té molt a perdre 'per la seva extremada feblesa'. La seva honra és un fonament de la societat. Per això, a fi de protegir-la, primer hi haurà el pare i després el marit» ${ }^{4}$.

Aquesta idea es manifesta en l'arquitectura de ciutats com Barcelona. Roig, que la reelabora en la seua literatura i li dedica també un ampli capítol en Digues que m'estimes encara que sigui mentida, troba en l'estructura del barri de l'Eixample una nova concepció de la ciutat, més humana, més càlida. Fruit del pla d'un enginyer del segle XIX, Ildefons Cerdà, l'Eixample desplaçarà el centre de la ciutat de Barcelona més enllà de les seues muralles; el mar i la muntanya seran ara les seues fronteres. "Cerdà tingué un somni quadriculat on les línies es repetien fins a l'infinit" ${ }^{5}$. Va concebre així blocs octogonals, amb amplis

2. RoIG, Montserrat: Digues que m'estimes encara que sigui mentida, Barcelona, Edicions 62, 1991, p. 124.

3. Wigley, Mark: «Sense títol: l'allotjament del gènere», en Beatriz Colomina (ed.): Sexualitat i espai. El disseny de la intimitat, Barcelona, Edicions UPC, 1997, p. 212.

4. RoIG, Montserrat: Digues que..., op. cit., p. 137.

5. Ibid., p. 136. 
xamfrans on s'encreuarien les vies i "la gent tindria temps d'aturar-se i mirar-se als ulls» ${ }^{6}$. A l'interior de cada edifici, lluny del tràfec dels carrers, protegit de l'exterior, Cerdà va situar-hi patis i galeries envidrades. Aquest espai és el que habitaven les senyores burgeses que protagonitzen algunes de les novel-les de Roig. "La senyora s'imagina el món tot mirant la volta blava que cap, ben just, dins un quadrat: el que fan els patis de l'Eixample»'

Balcons de retorçuts dissenys modernistes, galeries de llum tamisada, patis amb estudiada vegetació... Aquestos llocs fascinen Roig, que troba, "darrere de cada porticó, [...] una història per a narrar ${ }^{8}$. Les històries de senyores recloses en la part darrera de pisos immensos, que procuren situar-se i establir un espai propi apart del que els és vedat:

«Les senyores del Eixample sabien que, al davant, hi havia el despatx del seu home, advocat o fabricant de filats. Ella va construir tot un món a la part del darrere, a les galeries, a les saletes i als menjadors. Allí s'hi escoltava, en diversos capítols de vegades deslligats, tot un cabal de literatura parlada»".

Ara bé, la construcció d'aquest món interior, privat, no implica necessàriament un sentit de la propietat: en aquests casos no esdevé la cambra pròpia que imagina Virginia Woolf en el conegut assaig que la du per títol. És sovintejat per les dones de la família, però, com afirma Françoise Collin, «no es a título personal, como personas, que se encuentran allí, sino como esposas y madres. La casa está concebida con relación a una pareja, una familia, [...] de manera que una mujer siempre está allí entregada a la otra parte.» ${ }^{10}$

És el despatx del marit l'únic espai individual de la casa, el límit intern de l'autoritat de la dona dins de la llar. En aquest sentit, Roig coincideix amb Mark Wigley, qui afirma que «el primer espai veritablement privat fou el gabinet de l'home, una petita cambra tancada adjacent al dormitori on ningú més pot entrar, un espai intel-lectual més enllà d'aquell de la sexualitat» ${ }^{11}$. S'hi guarden els documents financers i genealògics de la família, els seus secrets: els afers públics s'amaguen i es protegeix a l'espai privat, a l'interior. Segons Wigley, ací és on naixen les memòries -en l'origen, registres destinats a confirmar el prestigi de la família, que van anar, a poc a poc, derivant en l'exaltació de l'individu i del seu poder i projecció en l'àmbit públic.

Les memòries que, malgrat tot, escriuen les protagonistes de Roig no parlen de poder ni de representació pública. En la mesura en què els és vedat l'accés a aquest àmbit (i també al despatx, l'indret que el guarda dins de la casa), els registres de la seua percepció del món són privats, interiors, sentimentals, aliens

6. Ibid., p. 136.

7. Ibid., p. 145.

8. Ibid., p. 148.

9. Ibid., p. 149.

10. Collin, Françoise: «Espacio doméstico. Espacio público. Vida privada», en Ciudad y mujer. Actas del curso: urbanismo y mujer. Nuevas visiones del espacio público y privado, Málaga-Toledo, 19931994, p. 235.

11. Wigley, Mark: Op. cit., p. 218. 
al transcurs de la història. Fragmentaris, per tant: diaris, cartes, monòlegs... La literatura privada que Roig imagina darrere de cada finestra. Barbara Łuczac ${ }^{12}$ assenyala el caràcter subversiu d'aquesta estratègia memorialística femenina en la literatura de Roig, que a més va inevitablement unida a la percepció de les dones que observen la ciutat des dels espais frontera (galeries, balcons...):

"Gràcies al seu caràcter subversiu i transgressor, la paraula de les memòries femenines de Roig es planteja redefinir la relació entre la dona i l'espai del carrer i, per extensió, el de la ciutat, entesos com a territoris de dominació lingüística i cultural masculina».

Així doncs, Roig atribueix als personatges femenins de les seues novel-les una capacitat discursiva, precària -sense una cambra pròpia- però creadora i, per tant, d'índole pública.

\section{EN LA CIUTAT: MIRADES NOVES, DONES FLÂNEUR?}

Si bé l'escriptura de memòries exerceix un punt de subversió contra el silenci imposat, és la lectura de la ciutat, la possessió íntima dels espais urbans, el dret que situa algunes protagonistes de Roig en la vi(d)a pública. Tanmateix, és la figura de la dona flâneur la que trobem en les pàgines de la seua literatura, o només una versió esbiaixada?

La novel-la Ramona, adéu (1972) constitueix el primer graó en la llarga trajectòria dels personatges femenins de Roig a la recerca d'una identitat pròpia, que culminarà en obres posteriors; concretament, El temps de les cireres (1977) i L'hora violeta (1980). En aquestes novel-les, personatges com Natàlia o Norma envaeixen l'espai públic en qualitat de professionals emancipades, observadores i creadores de realitat -mitjançant la fotografia i la creació literària, respectivament. Però són nous temps, temps de primavera i una nova esperança: Natàlia és la primera que llig els carrers de la ciutat, la primera possible flâneur de l'obra de Roig, la que troba, en el barri de Santa Maria del Mar, els arrels que necessita per trobar-se i esdevenir, de retruc, pont entre generacions, transmissora de la identitat catalana -diluïda fins el no-res en personatges com el seu nebot Màrius, fill del franquisme. Però no podem comprendre l'apropiació de l'espai públic efectuada per Natàlia sense analitzar, primer, els fracassos de les dones que la precediren en el temps, i també el primer èxit parcial d'una d'aquestes protagonistes -si és que el podem considerar així: el de la més jove de les Mundetes de Ramona, adéu, que aconsegueix trencar el cercle viciós que la lliga a la genealogia familiar quan decideix anar-se'n de casa.

12. ŁuCZAC, Barbara: "L'espai de les memòries en Digues que m'estimes encara que sigui mentida de Montserrat Roig», en Joaquim Espinós - Anna Esteve - M. Àngels Francés - Antoni Maestre Juli Martínez (eds.): Memòria i literatura. La construcció del subjecte femeni. Periodisme i autobiografia, Alacant - València, Denes, 2002, p. 119. 


\subsection{Sobre el concepte de flâneur}

Baudelaire definia, en la seua cèlebre obra El pintor de la vida moderna (1863), el terme flânerie com l'activitat del poeta espectador, sobirà de les multituds, passejant per la ciutat per a trobar aquelles meravelles que ocuparan, per un breu i lluminós instant, la seua mirada i que, per tant, completaran la seua identitat, incompleta en l'origen; satisfaran la seua existència, insatisfeta si no; reemplaçaran, en fi, l'angoixa amb la vida. ${ }^{13}$ És l'home de la multitud, no en la multitud, perquè té la capacitat de passar inadvertit, de no deixa empremta alguna en la retina dels vianants amb què es creua, de ser anònim i trobar-se $a$ casa en cadascun dels racons de la ciutat. I tot això perquè "completion requires an escape from the private sphere. The hero of the modern life is he who lives in the public spaces of the city» ${ }^{14}$. Sense aquesta fugida lluny de l'interior domèstic, l'home llangueix com una perla closa en una inadvertida ostra.

Tant Baudelaire com Benjamin associen la figura del flâneur a la modernitat i la urbanitat contemporània. No és casual que emergira en aquest context: és fruit d'un paisatge social i cultural en procés de canvi, de l'intent dels escriptors d'extraure'n el significat.

Aquesta masculinització de la figura del flâneur ha atret l'atenció de la crítica feminista més recent. Déiem abans que Janet Wolff ${ }^{15} \mathrm{i}$, també, Griselda Pollock ${ }^{16}$ troben que les dones contemporànies al flâneur de Baudelaire o Benjamin tenen una percepció diferent de la ciutat moderna, una visió que ha estat obviada i silenciada com a secundària; la manca de llibertat femenina per caminar i mirar sense traves $i$, sobretot, sense ser observades fan impossible trobar-ne una versió alternativa: «there is no female equivalent of the quintaessential masculine figure, the flâneur: there is no and could not be a female flâneuse ${ }^{17}$. Priscilla Parkhurst Ferguson ${ }^{18}$ analitza la figura en diversos autors i addueix, segons aquestos, diverses raons per les quals la dona no pot desenvolupar l'activitat de flânerie. En primer lloc, pel fet que, per naturalesa, és incapaç de sostraure's als encants de la ciutat del consum: desitja els objectes que exposen els aparadors i no pot assolir, per tant, la distància estètica fonamental per a la superioritat del flâneur ${ }^{19}$; la dona, a més, estableix lligams i relacions amb la realitat que l'envolta en lloc de contemplar-la des d'una distància de seguretat ${ }^{20}$. La raó més important, però, per la qual les dones no poden ostentar la identitat

13. Tester, Keith: «Introduction» a Keith Tester (ed.): The Flâneur, London and New York, Routledge, 1994, p. 4.

14. Ibid., p. 5.

15. WolfF, Janet: "The Invisible Flâneuse. Women and the Literature of Modernity», en Feminine Sentences. Essays on Women and Culture, Los Angeles, University of California Press, 1990, pp. 3450 .

16. Pollock, Griselda: «Modernity and the Spaces of Femininity», en Vision and Difference: Femininity, Feminism and the Histories of Art, Londres, Rouledge, 1988, pp. 50-90.

17. Ibid., p. 71.

18. Parkhurst Ferguson, Priscilla: «The flâneur on and off the streets of Paris», en Keith Tester (ed.): The Flâneur, London and New York, Routledge, 1994, p. 22.

19. Ibid., p. 27.

20. Ibid., p. 31. 
del flâneur, és que són components essencials del drama urbà que aquest observa, són objectes que consumir o dels quals gaudir, conjuntament amb la resta d'espectacles que ofereix la ciutat ${ }^{21}$.

Roig també es mostra escèptica sobre la possibilitat d'una versió femenina del flâneur. En efecte, encara que ella, com a escriptora, mira i escriu-crea el món amb els seus ulls-, és conscient que encara és mirada com a dona. Roig es pregunta:

«Ens trepitgen la mirada no tenint-la en compte, tot practicant allò que els mexicans en diuen ninguneo, una manera de no voler veure allò que tu veus? Hem deixat la finestra i hem baixat al carrer? La dona parla, però continua essent mirada. Feu la prova, poseu-vos un barret i entreu en un bar ${ }^{22}$.

Sense l'anonimat necessari, sense una metamorfosi prèvia d'objecte a subjecte, lliure per observar sense ser vist, les dones no poden llegir la ciutat com ho faria un flâneur. Per a Barbara Łuczac, és impossible trobar-ne una versió femenina en les pàgines de Roig -ni enlloc. Łuczac fonamenta la seua argumentació en la idea de la mirada bòrnia que Roig elabora en Digues que $m^{\prime}$ estimes encara que sigui mentida ${ }^{23}$ :

"Això vol dir que, en un ull, hi duem un pedaç, i això ens permet seguir mirant cap endintre, escoltar la nostra veu, la no expressada o no admesa, com la Gran Veu, la dels Sacerdots que regeixen els cànons a seguir, tant a la crítica com a les universitats, mentre que l'altre ull mira cap enfora, vola lliure, activament, sense ulleres fosques, ni càmeres, ni binocles. L'ull que mira cap enfora s'ha escapat del tema, ensopit, redundant, de la dona. L'altre, passa comptes. No podem ocultar que «encara» duem un pedaç».

Segons Roig, doncs, la dona mira en dues direccions divergents i simultànies: amb un ull mira enfora, lliure; amb l'altre, tapat per un pedaç, mira endins, es llegeix, s'analitza. Per a Łuczac,

«aquest pedaç que la dona duu en un ull condiciona la relació que s'estableix entre ella en qualitat de subjecte que mira i l'espai contemplat, i implica que la mirada amb què la passejant contempla la ciutat no pot ésser la d'un equivalent femení del flâneur, malgrat les similituds aparents. [...] La incapacitat d'escapar-se del tema de la dona, 'ensopit' i 'redundant', fa que la mirada femenina no pugui contemplar l'espai urbà de manera neutra o indiferent, com un espectacle essencialment aliè» ${ }^{24}$.

Euczac es refereix ací a la mirada del flâneur segons la definició que en fa Zygmunt Bauman, que la compara amb una instantània fotogràfica, un snapshot que "no hi veu i que confereix a l'experiència urbana un caràcter superficial,

21. Ibid., p. 27.

22. Roig, Montserrat: Digues que..., op. cit., p. 83.

23. Ibid., p. 81.

24. EucZAC, Barbara: Op. cit., p. 120. Alejandro Varderi també observa el caràcter introspectiu d'aquesta mirada bòrnia, com un boomerang, "mirada cega que veu vers l'interior, i en tornar es tanca sobre si mateixa». Vid. VARDERI, Alejandro: «Montserrat Roig: ulls enlaire! Mirades de dona vers la 'rosa de foc'», Catalan Review, vII:2 (1993), p. 192. 
epidèrmic, episòdic ${ }^{25}$. Sens dubte, si ens atenem a aquesta definició de la mirada del flâneur, sembla poc probable trobar personatges femenins en la literatura de Roig que s'hi adeqüen a la perfecció. Ara bé, el punt de partida d'aquest article és que sí que és possible trobar-hi una altra versió, una alternativa de mirada femenina, resistent, basada en una forta simbiosi amb la ciutat com a font d'identitat.

Per trobar, però, aquesta figura en la literatura de Roig cal efectuar el que Deborah Parsons ${ }^{26}$ anomena "a redefinition of the flâneur to acknowledge its related but distinct uses as a conceptual term and as socio-historical phenomenon.» En lloc de contradir Wolff i Pollock, Parsons basa la seua reelaboració del sinuós concepte de flâneur en dues premisses:

«first, that the concept of the flâneur itself contains gender ambiguities that suggest the figure to be a site for the contestation of male authority rather than the epitome of it, and secondly, that a mode of expression can be seen to develop in the late nineteenth and early twentieth centuries that emphasize observation of the city yet is distinct from the characteristic practice of the authoritative flâneur, comparable instead to the marginalized urban familiarity of the rag-picker ${ }^{27}$.

Per a Parsons, certes escriptores en llengua anglesa de finals del segle XIX i principis del XX elaboren aquesta metàfora alternativa de l'observadora urbana, possible gràcies a un context social que facilita una progressiva incorporació de les dones als espais públics de la ciutat. Aquest fenomen desafia l'especificitat masculina de la percepció estètica i urbana que representa el flâneur, i trau a la llum el que Parsons denomina "[the] women's highly self-conscious awareness of themselves as walkers and observers of the modernist city» ${ }^{28}$. Analitza així la narrativa d'escriptores com Virginia Woolf, Jean Rhys, Anaïs Nin o Doris Lessing, entre d'altres, per a les quals la ciutat opera no sols com un lloc o una imatge, sinó com a constituent d'identitat ${ }^{29}$. Amb la ciutat estableixen una connexió intensa que la revela com un palimpsest de capes d'història ${ }^{30}$; en paraules de Minnie Bruce Pratt, "[a] way of looking at the world that is more accurate, complex, multi-layered, multi-dimensioned, more truthful: to see the world of overlapping circles $»^{31}$.

En efecte, la percepció que les protagonistes de Roig tenen dels carrers de Barcelona no és epidèrmic en absolut: estableixen intensos lligams sentimentals amb l'espai que observen, hi arrelen el seu passat, present i futur. De la ciutat, en fan memòria, i és el centre de gravetat on sempre acaben per tornar. Com les protagonistes d'Anaïs Nin o Doris Lessing, prefereixen "wandering away from

25. ŁUCZAC, Barbara: Op. cit., p. 121.

26. Parsons, Deborah: Streetwalking the Metropolis. Women, City and Modernity, Oxford, Oxford University Press, 2000, p. 5.

27. Ibid., p. 6.

28. Ibid.

29. Ibid., p. 7.

30. Ibid., p. 10.

31. En PARSONS, Deborah: Op. cit., p. 15. 
planned pathways to backstreets, where they find the myths and memories of both the city and themselves» ${ }^{32}$. És el cas, per exemple, de Mundeta Claret, que en els carrers de Barcelona efectua la seua particular revolta i acaba fent un primer intent de fugida -precari i parcial, però amb la importància de serne el primer pas. Es manifesta millor en el personatge de Natàlia, que retorna a Barcelona després d'una estada a Londres i reconeix, en els seus carrers, la identitat del poble a què pertany. Si bé no són flâneuses en el sentit tradicional de terme, aquestes protagonistes de Roig sí que podrien ser, segons els paràmetres de Deborah Parsons i les puntualitzacions terminològiques d'Anke Gleber, ${ }^{33}$ flâneurs femenines de mirada resistent, subjectes i no sols objectes a la mercè del consumidor masculí. Mundeta Claret -i Natàlia després- és, en part, càmera, espectadora i, finalment, directora d'un text propi, en oposició a Mundeta Jover i Mundeta Ventura, dones-perles enclaustrades que llangueixen a l'interior. Vegem-ho.

\section{MUNDETA JOVER: LA VIDA DES D'UN BALCÓ}

La geografia literària de Roig comença en universos closos. La seua primera novel.la, Ramona, adéu (1972), ho demostra. A través d'una complexa estructura fragmentària i enllaçada temàticament per imatges i motius comuns, hi veiem dibuixats els moments clau de la vida de tres generacions de Mundetes ${ }^{34}$ que comparteixen, a més del nom, idèntiques preocupacions i experiències, fins al punt que els temes principals de la novella es desenvolupen per triplicat. ${ }^{35}$

De les tres dones, Mundeta Jover és la que millor representa els valors de la burgesia barcelonina de principis de segle. La seua interacció amb els espais que habita és intensa i en determina la visió del món, que coneixem gràcies a fragments del seu diari personal. A través d'aquesta escriptura privada

32. Ibid.

33. Gleber, Anke: "Female Flânerie and the Symphony of the City», en Katharina von Ankum (ed.): Women in the Metrópolis, Berkeley - Los Angeles - London, University of California Press, 1997, p. 84. Gleber prefereix el terme femme flâneur al de flâneuse perquè, segons ella, "the term flaneuse bears associations of the 'typical' female, of 'necessarily' menial occupations such as those of the Friseuse (female hairdresser) or Maseuse (female massage worker), the latter two carrying contingent, sexually suggestive, and discriminatory connotations.» Ibíd, p. 69.

34. El crític Àlex Broch situa la novel-la entre les de cicle familiar i social dels setanta, encara que li reconeix unes característiques de construcció que la diferencien de la resta. En efecte, les biografies dels tres personatges femenins de la novel-la, Ramona Jover (1874-1970), la seua filla Ramona Ventura (1909-) i la seua néta Ramona Claret (1949-) «són relats encadenats i successius més que no pas una estructura interrelacionada i cohesionada que expliqui l'evolució complexa d'un nucli o cèl-lula familiar amb els diversos personatges que hi intervenen". Vid. Broch, Àlex: Literatura catalana dels anys setanta, Barcelona, Edicions 62, 1980, pp. 72-73.

35. Bellver, Catherine G.: "Montserrat Roig or the Creation of a Gynocentric Reality", en J. L. Brown (ed.): Women Writers of contemporary Spain. Exiles in the Homeland, Associated University Presses Inc., Londres, 1991, p. 221. En efecte, segons Àlex Broch, cadascuna de les tres Ramones s'explica per la seua relació sentimental, per la condició del seu oponent masculí i per la relació dialèctica que estableixen amb el marc històric en què es troben. Vid. Broch, Âlex: «Maria Aurèlia Capmany i Montserrat Roig o el temps com a memòria collectiva", Catalan Review, VII:2 (1993), p. 31. 
observem la decadència quasi vertical dels ideals i les il-lusions romàntiques d'una dona apassionada i lúcida, que s'enfonsa lentament en una quotidianitat insuportablement gris. El seu matrimoni esdevé presó: «marriage, as such, represents increasing confinement in a narrowing world. ${ }^{36}$

L'adolescència de Mundeta apareix retratada com una edat idíllica. La vida encara li ofereix un horitzó de temps per a descobrir el món, i no importa si a penes s'albira des de l'interior: «He passat les hores mortes de la meva vida mirant al carrer, procurant endevinar-hi un bocinet de cel, una llenca, amb núvols que s'estiren i s'arronsen. Així no em posava trista perquè els nuvolets m'explicaven els seus viatges.» ${ }^{37}$ Mundeta imagina destinacions exòtiques des de la finestra, o es creu heroïna de les romàntiques històries que llig a les golfes, un espai silenciós, ple d'andròmines velles, secundari, però a penes sovintejat per cap altre membre de la família. A les golfes és on les crítiques nordamericanes Sandra Gilbert i Susan Gubar ${ }^{38}$ situen la seua particular boja, símbol de l'ansietat d'autoria de les escriptores que gosen prendre la ploma en un món reservat als homes; a les golfes és on Mundeta transgredeix també l'ordre establert llegint novel-les que l'ajuden a evadir-se vers mons exòtics, altrament fora del seu abast. Un cert instint narcisista la du a desitjar espies observant-la, bé com l'actriu protagonista d'algun drama dels que llig, bé amb connotacions eròtiques, en la banyera de marbre rosa de que gaudeix, sola, en el seu viatge de noces a París: "Quan em banyo em penso que sóc la Casta Susana i que m'esguarden per la finestrella $»^{39}$.

París representa el glamour sols a l'abast de burgesos adinerats com l'home $a m b$ qui s'acaba de casar. És l'espai del somni: «em veig dansant amb ell en una de les terrasses de Versailles, sota el clar de la lluna, i uns desmais al fons, entre gent molt jove i molt bella, amb vestits majestuosos i joies rutilants» ${ }^{40}$. Tanmateix, és en aquesta ciutat que no podrà posseir quan s'adona que, per la seua condició, mai satisfarà l'ànsia d'un quelcom indefinible amb què sentir-se viva. La seua experiència de París s'assembla sorprenentment a la de Barcelona, els carrers de la qual tampoc li són propis: «Els senyors que passegen per les Tulleries, amb la boira grisa i el fred de l'hivern, fan la mateixa cara de satisfacció que els senyors barcelonins quan davallen pel passeig de Gràcia»»11. Com apunta Alejandro Varderi ${ }^{42}$,

«solament com 'la reina d'en Francisco Ventura' (p. 43) el cos podrà seduir, la casa serà habitable, i París li semblarà 'tan mesquina i provinciana com Barcelona';

36. Rogers, Elizabeth: "Montserrat Roig's Ramona, adiós: A Novel of Suppressions and Disclosure», Revista de Estudios Hispánicos, 20.1 (1986), p. 107.

37. Roig, Montserrat: Ramona, adéu, Barcelona, Edicions 62, 1976 (1972), p. 32.

38. Gilbert, Sandra - Susan Gubar: The Madwoman int the Attic. The Woman Writer and the NineteenthCentury Literary Imagination, Yale UP, 1979.

39. RoIG, Montserrat: Ramona..., op. cit., p. 42.

40. Ibid., p. 43.

41. Ibid., p. 47.

42. VARDERI, Alejandro: "Montserrat Roig: ulls enlaire! Mirades de dona vers la 'Rosa de Foc'», en Catalan Review, VII:2 (1993), p. 191. 
sense ella adonar-se que, en circumscriure a la jurisdicció de l'altre, està hipotecant la seva mirada i per tant condemnant el seu llenguatge dins d'un onanisme del qual no sortirà mai més».

Amb la mirada hipotecada en l'origen, doncs, s'hi sent estrangera i decebuda; la seua illlusió per descobrir un món diferent fracassa en el que intueix que serà l'únic viatge de la seua vida, però sobretot lamenta passar per la Ciutat de la Llum "com aquell qui fa visites, d'esquillentes» ${ }^{43}$.

A la tornada, la realitat en la nova casa, a Gràcia, és encara més desoladora. No s'hi troba en el paper que té assignat, no sap fer les feines domèstiques però no es refia de les minyones, en aquesta perifèria ${ }^{44}$ de l'autèntica ciutat: "Tot seria diferent si visquéssim a Barcelona, però aquí, encofurnada en aquest cau de xafarderia i de vulgaritat! $\aleph^{45}$. N'enyora l'empremta de sensacions que la Rambla li deixa en la memòria, els passeigs, sempre del braç del seu home, els diumenges: «em captiva l'olor que alenen les acàcies i els baladres que pugen de la Rambla. És una olor de mar, viva i engrescadora» ${ }^{46}$.Canvia incessantment els mobles de lloc, intentant redecorar al seu gust l'espai que habita per veure si, així, desordena també la rutina gris que presideix la seua vida, però fracassa en tots dos objectius.

Francisco, el seu home, i els que, com ell, estan a punt de patir el desastre econòmic que va implicar per al país la pèrdua de les colònies americanes en el tombant de segle, habiten el saló d'estil que se situa en el centre de la casa. A ella sols li és permés accedir-hi amb la imprescindible i protocolllària safata de té i pastes; per descomptat, els afers financers del nucli familiar de què forma part li són vedats: "En Francisco no em vol explicar com van les coses, diu que no les entendria ${ }^{47}$. Ella escolta, observa i intueix la catàstrofe que se'ls ve damunt. Somia amb les llunyanes illes de clima tropical i enveja la pobra gent que s'embarca a buscar-hi fortuna, a la recerca d'aquell "paradís desconegut, enorme $»^{48}$ que descriu cercles concèntrics en la seua ment.

Si aquesta sensació de tancament i vida artificial la sumeixen cada vegada més en un desengany permanent, l'experiència traumàtica d'un avortament natural acabarà de mostrar-li com serà la seua vida a partir d'aquest moment: la dimensió simbòlica de l'entrada del 28 de setembre és simptomàtica del que serà el seu futur. Mundeta, de passeig amb Francisco per Vista Alegre, se sent sobtadament presa d'una eufòria boja, de un «desig irreprimible de llançar-me a volar pel damunt de Barcelona»49, i comença a córrer seguida de prop pel seu home, desconcertat i avergonyit per l'espectacle: «m'afigurava que era

43. RoIG, Montserrat: Ramona..., op. cit., p. 46.

44. Gràcia era una població autònoma de les rodalies del nucli urbà de Barcelona: amb l'expansió de la ciutat, va passar a formar-hi part. Els prejudicis classistes de la protagonista li impedeixen veure-la com part de la Barcelona que coneix i estima.

45. RoIG, Montserrat: Ramona..., op. cit., p. 50

46. Ibid., p. 91.

47. Ibid., p. 56.

48. Ibid., p. 57.

49. Ibid., p. 64. 
una papallona, gràcil, delicada, llangorosa, sempre a punt d'olorar una flor» ${ }^{50}$. L'ànsia de volar que la posseeix acaba tristament: una "escalfor molt dolça» entre les cames, que en un principi podria semblar una experiència pròxima a l'orgasme i que connecta amb la insatisfacció de la seua vida sexual, és tanmateix l'hemorràgia produïda per l'avortament natural d'un fill que no sabia que esperava. En la febre de la convalescència, somia un monstre meitat dimoni meitat dona: «em cridava i m'abraçava i vaig veure els meus morts, els meus pares, el iaio de Siurana, que em deien que era una perduda $»^{51}$. S'hi manifesta així la seua noció de culpa per desitjar altres mons, per menysprear l'entorn en què ha nascut i la tradició que pesa sobre ella com una llosa: el monstre sembla l'encarnació del sentiment d'insatisfacció permanent que l'angoixa, la demonització dels plaers terrenals que ansieja, distorsió pròpia de l'imaginari religiós en què ha estat educada.

La seua visió rejoveneix amb la mudança a un pis nou en el bell cor de la ciutat, a l'Eixample que comença a albergar la burgesia del moment i esdevé punt neuràlgic de la vida social de principis del segle XX. Els espais frontera de la casa adquireixen color i so: «els quatre balcons són plens de plantes, d'anemones, assutzenes, hortènsies, clavells, corretjoles. [...] També he comprat ocells, caderneres, canaris i un periquito de color verd desmai que em crida: 'Ramona, ven'52. És aquest espai l'escenari on es produirà el clímax de la seua vida, la passió per un jove estudiant que ella observa i imagina en el balcó d'una pensió a l'altre costat del carrer, com una moderna Güelfa. ${ }^{53}$

La visió de la figura esvelta i jove de l'estudiant li encén a Mundeta el desig adormit per anys d'insatisfacció sexual. ${ }^{54}$ Ell acaba per descobrir-la, i des de l'altra banda del carrer esdevé sense saber-ne un voyeur còmplice: "Avui l'estudiant m'ha resseguit el cos mentre jo regava les plantes del balcó»" ${ }^{55}$. Del desig silenciós naix l'intercanvi de cartes, i coneix el seu nom, Víctor Amat (ben simbòlic, d'altra banda). ${ }^{56}$

Mundeta i l'estudiant tenen trobades fugaces pels carrers de Barcelona, però no és fins a un passeig per la Barceloneta, el barri de pescadors on ningú sembla advertir la seua pecaminosa presència, quan es produeix se el primer contacte

\section{Ibid.}

51. Ibid., p. 65.

52. Ibid., p. 104.

53. Des d'una finestra s'enamora Güelfa del jove Curial, en la clàssica Curial e Güelfa, obra anònima del segle XV, una cita de la qual obre la novel·la. D'una manera similar començarà la relació entre Mundeta i l'estudiant.

54. «Endevino que els seus ulls són vius, flamejants, a voltes tristos, i que els llavis li deuen tremolar davant d'una cosa bella, uns llavis ardents, uns llavis que parlen per un cor fogós, uns llavis...» RoIG, Montserrat: Ramona..., op. cit., p. 108.

55. RoIG, Montserrat: Ramona..., op. cit., p. 112.

56. Hi contrasten els poemes que rep d'ell, en català (per a ella, la llengua més sincera, pròpia) amb els que li escriu el marit, en castellà (que ella sent distant i fred). Segons Alejandro Varderi (Op. cit., p. 193), amb les cartes de Víctor Mundeta recobra la catalanitat que inconscientment havia perdut en casar-se. Malgrat tot, l'estudiant no privilegiarà un diàleg sinó que portarà a terme una doble intrusió dins el llenguatge i el cos de Mundeta, com després veurem. 
físic entre els dos. Mundeta es desinhibeix dels seus prejudicis classistes, mesclant-se amb gent que abans hauria mirat de lluny amb aprensió; hi és lliure perquè no és observada: «Hem entrat en una taverna plena de mariners $\mathrm{i}$ de pescadors i ningú ens ha fet cas. Això m'ha estranyat però m'ha esbargit la vergonya» ${ }^{57}$.

L'última missiva de Víctor la cita en el parc de la Ciutadella per al comiat: en acabar el curs, ell ha de tornar al poble dels seus pares. Mundeta es debat entre els negres presagis del seu confessor i el desig urgent; finalment es decideix a anar al seu encontre. La freda pluja contribueix a ocultar-la mentre transgredeix les normes que haurien de retenir-la a casa, com la respectable senyora que és, i més encara en un dia de tempesta. Descriu cercles, vol i no vol arribar-hi: "Durant tot el camí no vaig fer més que giragonses, semblava acorralada ${ }^{58}$. La Ciutadella no és la mateixa dels dies de sol: hi regna un silenci ombrívol, sols interromput pel so del vent gelat que li travessa el cos, atrapat en el fastuós i pesat vestit mullat, i la ment, turmentada per la culpa. Sols l'estàtua de Venus desafia, solitària i ardida, la pluja. Però ella no és valenta com Venus i Víctor ha deixat de ser l'amable estudiant que l'admira en silenci:

«No veia res més que l'ombra, l'ombra que s'acostava cada cop més definida, més exacta, amb els ulls sortits, sangonosos. I vaig sentir una massa que em queia a sobre, que m'estrenyia la cintura, que em ficava la mà dintre el vestit... ${ }^{59}$.

La noció de pecat transforma la trobada en una amenaça de violació, o almenys així és com ella ho veu. Mundeta s'autoimposa un càstig exemplar per haver gosat desafiar la moral de l'època en què viu; en ella operen les convencions que, segons Anke Gleber ${ }^{60}$, contribueixen a impedir l'eixida de la dona als carrers que no li pertanyen. En efecte, encara que ha reunit el valor per arribar a la Ciutadella, aquest coratge l'abandona davant la figura masculina, probablement contaminada en la seua ment per les amenaces dels homes encarregats de protegir-la de les agressions que podria patir si vaga sola per la ciutat; elements físics com l'alta costura que ella, com a burgesa, sol vestir, fan més pesat el camí, carregada com va de penediment i angoixa.

La següent entrada del diari relata la fugida de Mundeta dels braços de l'estudiant; aconsegueix agafar un cotxe i arriba a casa malalta de fred i de pànic. El seu marit la rep i la gita en el llit, on ella passa dies i nits febrils. El monstre que poblava els seus malsons reapareix ara per acusar-la d'adúltera; el desig insatisfet pren la forma de milers de mans que recorren el seu cos encés. En la seua imaginació, les veus dels seus avantpassats, l'autoritat del patriarca de la família, la turmenten amb els seus crits de condemna.

Després d'aquest episodi hi ha un silenci, en el seu diari, de vuit anys. En el transcurs d'aquest temps, Mundeta ha tingut una filla lletja i trista, que sembla haver heretat, amb el nom de sa mare, també la infelicitat: «Si haguéssim tingut

57. RoIG, Montserrat: Ramona..., op. cit., p. 133.

58. Ibid., p. 138.

59. Ibid., p. 139. 
un nen... un home és lliure, pot triar el seu camí. Una dona no hi té res a fer, en el món! „61. Mundeta, que un dia havia volgut volar lliure, esdevé en realitat un ítem més de la col-lecció de papallones que guarda el seu marit, precioses, de tots els colors $\mathrm{i}$ les formes, «fermades amb agulletes de plata i amb el cap de perla» ${ }^{62}$.

\section{MUNDETA VENTURA, ENTRE EL CAOS BÈL.LIC}

Mundeta Ventura hereta de sa mare el nom i la pena:

«La nena és lletja i trista. Té uns solcs a la cara que la fan escarransida i els ulls sortints, com si fossin de vidre. No serà feliç. Part de culpa la té en Francisco, posarli Ramona! Ell deia que era un nom preciós, un nom per a una noia sense fums ni pretensions. A mi em sembla un nom de poble, per a dones desgraciades ${ }^{63}$.

En efecte, el seu destí sembla determinat per aquestos negres presagis. La nena creix a l'ombra d'una mare sense esperança, intuint «que hauria de passar per la vida desapercebuda i agraint el fet de ser-hi» ${ }^{64}$. L'amor la desperta de la letargia en què està permanentment sumida; li aclareix la mirada: "tinc uns ulls que miren de debò perquè és la primera vegada que esguarden un home, el meu» ${ }^{65}$. L'Ignasi Costa és un jove anarquista, compromés amb uns ideals que ella no entén, que la inicia en una precària relació amb la tèrbola realitat política del 1934. L'enamorament li descobreix a Mundeta un instint de possessió quasi ferotge $^{66}$ i li revela aspectes d'ella mateixa que ni tan sols sabia que guardava: emparada en els models de conducta transmesos pel cinema del moment, la Mundeta-Greta (per la Garbo en La reina Cristina de Suecia) s'aventura pels carrers de Barcelona davant l'atònita mirada de la tieta Patrícia, diligent guardiana de la virtut de la nena:

«Tan poqueta cosa. Tenia raó, la seva mare. Per això apartà d'una revolada el braç de la tia Patrícia i començà a caminar de pressa. La Mundeta-Greta sentia com si res els crits desconcertats de la Patrícia que li pregaven de retornar [...] Però la MundetaGreta ja no la sentia, travessava el carrer Viladomat, el carrer Urgell, sempre en línia recta, sense sortir de la vora esquerra de les Corts Catalanes, l'empenyia una fúria nova, el desig de veure l'Ignasi, de comprovar, amb la presència de l'home que l'estimava, com es difuminaven les boires que l'havien atrapada tota la vida ${ }^{67}$.

Mundeta vola per la ciutat, però no la llig, no hi reconeix l'ambient tens que s'hi respira, hi és aliena: "El silenci que emplenava la ciutat semblava el preludi d'un gran soroll final. Però la Mundeta Ventura no recollia res d'això, la Mundeta-Greta remuntava les Corts, cada vegada més prop de la plaça de

60. Gleber, Anke: Op. cit., p. 73.

61. RoIG, Montserrat: Ramona..., op. cit., p. 145.

62. Ibid., p. 80.

63. Ibid., p. 145.

64. Ibid., p. 141.

65. Ibid., p. 128.

66. "el defensaria amb les urpes, si calia.» (Ibid., p. 129)

67. Ibid., pp. 142-143. 
la Universitat, atabalada, absent de l'espectacle públic» ${ }^{68}$. La seua alienació històrica li impedeix, també, arribar a entendre la profunda angoixa de l'Ignasi, qui se suïcida, trastornat per no haver estat capaç d'evitar la mort de dos companys en una operació de lliurament d'armes crucial per a la causa obrera.

Si bé aquesta cursa per una ciutat en suspens no deixa empremta alguna en la consciència històrica de Mundeta, una segona oportunitat li és donada en temps de guerra. L'episodi, narrat en forma de monòleg interior, se situa en plena guerra civil i narra la recerca de Joan Claret, el seu marit, entre les runes del cinema Colisèum, destrossat per un bombardeig. És la crònica d'un dia, una nit i un matí en què la Mundeta, morta de por i de fred, regira les escombraries dels edificis pròxims al cinema, on Joan havia de negociar la seua fugida vers el bàndol nacional. L'absència de respostes enmig del caos la duu al dipòsit de cadàvers, on espera tota la nit per si algun dels cossos mutilats per les bombes té el rostre del seu marit. Al llarg del camí es troba una sèrie de personatges anònims, caracteritzats per la indumentària i algun tret físic, que adquireixen dimensió simbòlica per tal com col-laboren en el desvetllament de la consciència d'ella. El senyor de la bata blanca, «l'adobador de cadàvers», és poeta i sobreviu com pot a l'olor de guerra i de mort que respira cada dia; el vell dels ulls de ploviscó, un anarquista que busca el seu nebot entre els morts, esdevé company en la tragèdia: entre els dos s'estableix una relació que haguera resultat insòlita, per no dir impossible, en circumstàncies normals. L'experiència vital del vell, que ha lluitat per la revolució i ha perdut un fill en la guerra, és un mirall en què Mundeta s'adona i s'avergonyeix de la seua ignorància. Com apunta Catherine Davies, ${ }^{69} \mathrm{el}$ seu és un autèntic descens als inferns, la recerca de la vida enmig de la mort. L'escena enllaça amb l'epíleg en què Mundeta, que s'ha vist obligada a afrontar els seus prejudicis de classe en la conversa amb l'anarquista, arriba a albirar la possibilitat d'una vida nova, individual, emancipada: "She does not find her husband and, as a consequence, she finds herself and meaning in her previously purposeless life $»^{70}$. La victòria de Franco, però, significa per a ella, com per a moltes dones de la seua generació, la immersió en la mort en vida, una claudicació contínua sota l'autoritat de Joan Claret, que la redueix a una mena d'ombra per a la resta dels seus dies. Sense un rol significatiu en la societat, la vida de Mundeta roman dispersa i fragmentària, com la mateixa narrativa que la descriu.

\section{EL COMIAT: MUNDETA CLARET}

Mundeta Claret és la menor de la nissaga Ventura-Claret. La seua trajectòria vital és contemporània a la de l'autora; experimenta el trasbals dels anys del canvi, amb la confluència de valors nous i ràncies tradicions que ancoren el personatge en una mena de cruilla existencial. És l'època de la militància

68. Ibid., p. 143.

69. Davies, Catherine: Contemporary feminist fiction in Spain. The work of Montserrat Roig and Rosa Montero, Oxford - Providence, Berg Publishers, 1994, p. 37.

70. Ibid., p. 38. 
marxista en la clandestinitat, les repressions de la policia i l'angoixa de la censura, mentre a les universitats s'alcen veus rebels que intueixen la davallada del franquisme i la proximitat de nous temps. Mundeta es troba en un ambient on ressonen proclames d'esquerra, on es parla de l'alliberament de la classe obrera però experimenta, de la mà dels mateixos companys, la mena de masclisme que encara es troba arrelat en la societat que habita. Amb la revolució sexual, Mundeta experimenta el conflicte entre la moral repressora en què ha estat educada (és filla d'un franquista i una dona atemorida i trista) $i$ les noves consignes, sàviament manipulades pels companys progressistes per obtenir rèdit sexual de desorientades burgesetes sentimentals com ella. De la crisi en sortirà una dona nova, no sense abans haver pagat les taxes d'una llibertat cara i solament parcial.

Mundeta Claret passeja Barcelona. Ho sabem, per exemple, gràcies a un títol explícit: «Una de les innombrables passejades que la Mundeta Claret féu, quan era jove, per Barcelona. ${ }^{71}$ El conte s'obri amb una citació de Cesare Pavese, sobre la incomunicació entre els cossos que comparteixen espai però no s'adonen, els uns dels altres, dels secrets guardats gelosament i la vida interior que oculten: "¿Et quedes parat de veure que els altres et passin pel costat i no sàpiguen, quant tu passes pel costat de tanta gent i tampoc no saps, no t'interessa quines penes tenen, quin secret cranc duen?»»2. El relat és el monòleg de Mundeta, on es combinen els seus pensaments i fragments de diàlegs amb l'Anna, companya de classe i de gresques nocturnes, i amb Jordi, líder universitari i company de llit. Mundeta parla entre les boires de l'alcohol: el seu discurs és caòtic i sovint absurd. ${ }^{73}$ Sobta l'absoluta necessitat de Mundeta de ser escoltada i la manca de suport que cal deduir del seu ambient: l'Anna que se li escapa contínuament amb comentaris de tipus intellectual i aires de superioritat, i els comentaris implícits de Jordi també són de burla: "Jordi, he fotut llibres aquesta tarda, i demà hi tornaré. ¿Dius que no me'ls llegiré? Ets un fill de puta! Vés-te'n, em menysvalores, eh? És clar, com que ets un home... Dius que això no té res a veure?»74. L'episodi acaba amb l'escena en què Mundeta, borratxa i furiosa per la indiferència de Jordi, provoca un "obrer que passa" amb un inequívoc menyspreu de classe: «La suor dels treballadors m'encanta! Eh, com et dius? Ets molt guapo i muy hombre! [...] Eh, mireu, em grapeja i se'm vol tirar, pel que es veu!» ${ }^{75}$. Els carrers de Barcelona no són, en aquesta ocasió, font d'identitat o objecte d'observació i lectura, sinó que guarden una explícita connexió amb els encontres sexuals esporàdics que cal esperar de dones que, com Mundeta, desafien els bons costums imperants i hi passegen de nit. I això és tan vàlid

71. RoIG, Montserrat: «Una de les innombrables passejades que la Mundeta Claret féu, quan era jove, per Barcelona", en Molta roba i poc sabó... i tan neta que la volen, Barcelona, Edicions 62, 1978, p. 99

72. Ibid., p. 99.

73. S'hi barregen temes d'activisme polític amb records d'infantesa, somnis, fragments de literatura en castellà (trossos d'una traducció de Mujercitas, de Louise M. Alcott), etc.

74. Roig, Montserrat: «Una de les...», op. cit., pp. 105-106.

75. Ibid., p. 106. 
per als anys de la hipocresia moral franquista com per als del desvetllament feminista i la revolució sexual; Anke Gleber ho comenta a propòsit d'un titular del periòdic Oxford Mail del 1979: "Any woman walking alone after dark invites trouble» ${ }^{76}$. I encara que Mundeta no camina, en aquesta ocasió, sola, sí que ho està en certa manera, com hem pogut deduir del seu monòleg (la tria d'aquesta estratègia no és, tampoc, casual): pertany a un món falsament llibertari de pressupòsits marxistes però experimenta la mateixa mena de masclisme que abans, ara en companys de militància esquerrana que utilitzen els pressupòsits de l'alliberament sexual per a la satisfacció pròpia. En aquesta escena, és ella qui tria el rol que vol desenvolupar, qui prefereix el paper assignat a les flâneuses que gosen recórrer els carrers nocturns: ella és una de les dones «more likely victims of rape, assault, intimidation, and other forms of harassment. ${ }^{\prime 7}$.

Aquesta masoquista tendència de Mundeta envers el risc del sexe es manifesta també en la mena de fascinació que sent per la ciutat: «Era una ciutat que l'atreia amb la força d'un amant cruel. ${ }^{78}$ És el centre del seu univers, hi té arrels profundes, i d'alguna manera sap que no se n'anirà mai, de Barcelona. "Ara, en el silenci entebeït de la nit barcelonina, desitjava sentir-se empassada, engolida, dins la seva somorta personalitat. No ser ningú entre un formiguer de ningús $»^{79}$. I en els seus carrers és on Mundeta acaba per abocar l'amargor de la traïció, on du a l'extrem les seues perilloses incursions en l'aire nocturn i es prostitueix voluntàriament, sols per demostrar que ho pot fer, si vol; i per rebutjar després, definitivament, el rol imposat per la tradició i la genealogia femenina familiar que pesa sobre ella com una llosa.

L'origen de la revolta -absurda i instintiva, però revolta al cap i a la fi- de la més jove de les Mundetes és la traïció del seu amant, cruel com la ciutat, amb l'Anna, «la meuca de la universitat». L'Anna, que paga la seua llibertat molt cara, "era coneguda com una mena d'estudiant prostituïda; però ho acceptava com un mal que residia en els altres i no en ella» ${ }^{80}$. Mundeta, feta "de petites lleialtats, mesquines, subjectes als instints ${ }^{81}$, se sent atreta per aquesta mena d'independència però no és capaç d'assolir-la. "Si l'Anna era una meuca, per què no ella», es pregunta, amunt i avall per la carretera de Sarrià. "És com anar de puta, per a l'inrevés ${ }^{82}$. Amb el vestit que duu queden clares les seues intencions, pensa; caldria que hi afegírem, a més, la seua sola presència en aquella carretera flanquejada per prostíbuls. El conductor d'un esportiu la convida a pujar-hi; fan camí vers un meublé mentre ella intenta estar a l'alçada del paper que ha volgut interpretar. "M'admiraran i pensaran que sóc una dona emancipada. I que no els necessito per a res» ${ }^{83}$.

76. Gleber, Anke: Op. cit., p. 73.

77. Ibid., p. 73.

78. RoIG, Montserrat: Ramona..., op. cit., p. 93.

79. Ibid., p. 95.

80. Ibid., p. 80.

81. Ibid., p. 94.

82. Ibid., p. 105.

83. Ibid. 
Després, "bon vent i barca nova» ${ }^{84}$. Amb l'aire fresc de la matinada, Mundeta veu la ciutat d'un altre color. L'explotació sexual a què se sotmet per despit és el graó més baix d'una llarga trajectòria de victimització afectiva. El més baix i l'últim, però. El seu és un ràpid descens als inferns, del qual surt amb una nova consciència. Perquè, en lloc d'enfonsar-la en la més absoluta alienació i acabar amb la seua recerca d'una identitat pròpia, l'amargor de l'experiència funciona com a catalitzador i la llança en sentit contrari. Ni burgeseta sentimental ni prostituta: Mundeta fuig de tots dos extrems. Lentament, estripa els bitllets que s'acaba de guanyar i deixa enrere tota una etapa; amb els bocins de paper i l'alba, trenca amb antigues recances i pren, finalment, un nou rumb lluny del silenci i el cercle viciós en què es troba immersa. Experimenta el que Anke Gleber denomina «the persistent, real, and material limitations on women's access to the street ${ }^{85}$ : fins $i$ tot representa l'única forma femenina present en el carrer que és real i perceptible. Ara bé, contràriament a les prostitutes reals, que no posseeixen ni l'espai ni, en última instància, el propi cos, ella invalida l'acte mercantil que acaba de tenir lloc destruint els diners que li han pagat i transformant-lo en un acte de voluntat. I una promesa de canvi. La seua presència en l'espai públic, malgrat les conseqüències explícites d'aquesta transgressió, n'indica la ferma determinació de localitzar una experiència pròpia de la ciutat i, per extensió, de la seua vida. Pren la decisió de partir, dóna títol a la novel.la i, per primera vegada, se n'ix del patró que les seues predecessores havien dibuixat per a ella.

\section{CONCLUSIONS PROVISIONALS}

La interacció de les protagonistes de Ramona, adéu amb l'espai que les envolta és, com hem vist, intensa: a la ciutat de Barcelona les arrela un amor profund que, tanmateix, no esdevé aprenentatge significatiu fins a la més jove de la nissaga (i encara). La mirada de Mundeta Jover li retorna la seua pròpia imatge, reflectida en els vidres de la galeria interior, on llangueix com la perla inadvertida de què parlava Baudelaire: a ella no li és donada la possibilitat de triar si vol completar la seua identitat en els misteriosos carrers que recorre el poeta flâneur. En canvi, escriu memòries en un espai prestat, exercint així una peculiar transgressió -insuficient, en qualsevol cas. París és un somni fora del seu abast; els carrers de Barcelona també ho són, encara que, per breus moments de fugissera glòria, tasta la llibertat de l'anònim i experimenta l'amor, que dels ideals romàntics davalla a l'abisme de la noció de pecat i culpa. La seua infelicitat es transmet com una malaltia a la seua filla, arraulida i trista: Mundeta Ventura, tanmateix, també desafiarà el seu confinament a l'interior a la recerca de l'amor, que l'ompli de vida l'estiu del 1934. Novament, el fracàs va de la mà de l'alienació històrica en què es troba el personatge: de la mateixa manera que no viu ni llig els carrers d'una Barcelona en la tensió de la preguerra,

84. Ibid., p. 107.

85. Gleber, Anke: Op. cit., p. 73. 
tampoc no comprén l'home que estima ni sap evitar-ne la mort. Paradoxalment, és amb la guerra, que capgira les convencions prèviament establertes, quan ella albira que un nou futur és possible; això no obstant, la història escrita pels vencedors s'encarrega, de nou, de retornar-la a l'espai domèstic que havia gosat abandonar. I no és fins que arriba el canvi, als anys de davallada del franquisme i l'adveniment de la Transició, que Roig fa possible la versió femenina alternativa al flâneur que proposava Deborah Parsons, això sí, amb unes quantes dècades de retard respecte de les escriptores angleses que Parsons estudia -retard comprensible, d'altra banda, si fem una ullada a la repressió i la misèria de l'Estat espanyol durant el període de temps que envolta la guerra civil espanyola. La figura de Mundeta Claret és una nova versió de dona a la recerca d'una identitat basada, ara sí, en una consciència històrica, precària, instintiva, però amb la força suficient per empènyer-la fora de la casa que ha habitat des de sempre. La conquesta de l'espai públic passa per una insòlita i absurda assumpció del paper de prostituta, experiència traumàtica des de la qual és capaç de remuntar i assolir la capacitat per rebutjar, d'aleshores ençà, aquest $\mathrm{i}$ els altres papers atorgats a les dones de la seua condició. Mundeta Claret és l'única que no hi roman, tancada: és una possible esperança de futur.

\section{BIBLIOGRAFIA}

BRoch, Àlex: Literatura catalana dels anys setanta, Barcelona, Edicions 62, 1980.

- "Maria Aurèlia Capmany i Montserrat Roig o el temps com a memòria col-lectiva", Catalan Review, vIr:2 (1993), p. 21-37.

Collin, Françoise: "Espacio doméstico. Espacio público. Vida privada», en Ciudad y mujer. Actas del curso: urbanismo y mujer. Nuevas visiones del espacio público y privado, Málaga-Toledo, 1993-1994, pp. 231-237.

Colomina, Beatriz: "Murs dividits: el vouyerisme domèstic», en Beatriz Colomina (ed.): Sexualitat i espai. El disseny de la intimitat, Barcelona, Edicions UPC, 1997, pp. 56-85.

Davies, Catherine: Contemporary feminist fiction in Spain. The work of Montserrat Roig and Rosa Montero, Oxford - Providence, Berg Publishers, 1994.

Gilbert, Sandra - Susan Gubar: The Madwoman int the Attic. The Woman Writer and the Nineteenth-Century Literary Imagination, Yale UP, 1979.

Gleber, Anke: "Female Flânerie and the Symphony of the City», en Katharina von Ankum (ed.): Women in the Metropolis, Berkeley - Los Angeles - London, University of California Press, 1997, pp. 67-88.

ŁuCZAC, Barbara: "L'espai de les memòries en Digues que m'estimes encara que sigui mentida de Montserrat Roig", en Joaquim Espinós i altres- Anna Esteve - M. Àngels Francés - Antoni Maestre - Juli Martínez (eds.): Memòria i literatura. La construcció del subjecte femení. Periodisme i autobiografia, Alacant - València, Denes, 2002, pp. 115-124.

Parkhurst Ferguson, Priscilla: "The flâneur on and off the streets of Paris", en Keith Tester (ed.): The Flâneur, London and New York, Routledge, 1994, pp. 22-42.

Parsons, Deborah: Streetwalking the Metropolis. Women, City and Modernity, Oxford, Oxford University Press, 2000.

Pollock, Griselda: "Modernity and the Spaces of Femininity», en Vision and Difference: Femininity, Feminism and the Histories of Art, Londres, Rouledge, 1988, pp. 50-90. 
RoIG, Montserrat: "Una de les innombrables passejades que la Mundeta Claret féu, quan era jove, per Barcelona», en Molta roba i poc sabó... i tan neta que la volen, Barcelona, Edicions 62, 1978 (1970), pp. 99-106.

- Ramona, adéu, Barcelona, Edicions 62, 1976 (1972).

- Digues que m'estimes encara que sigui metida, Barcelona, Edicions 62, 1991.

Tester, Keith: "Introduction» a Keith Tester (ed.): The Flâneur, London and New York, Routledge, 1994, pp. 1-21.

VARderi, Alejandro: "Montserrat Roig: ulls enlaire! Mirades de dona vers la 'Rosa de Foc'», Catalan Review, VII:2 (1993), pp. 189-198.

Wigley, Mark: «Sense títol: l'allotjament del gènere», en Beatriz Colomina (ed.): Sexualitat i espai. El disseny de la intimitat, Barcelona, Edicions UPC, 1997, pp. 208-242.

WolfF, Janet: "The Invisible Flâneuse. Women and the Literature of Modernity", en Feminine Sentences. Essays on Women and Culture, Los Angeles, University of California Press, 1990, pp. 34-50. 